\title{
PENERAPAN SISTEM PERINGATAN DINI SUNGAI KELAY UNTUK PENGAMANAN RESIKO BANJIR PADA PIT BLOK-7 TAMBANG BINUNGAN - PT BERAU COAL
}

\author{
Tiara Andrianie Putri ${ }^{1)}$, Ahmad Baiquni ${ }^{1)}$, Muhammad Cahyono ${ }^{2)}$ \\ ${ }^{1)}$ Departemen Geoteknik dan Hidrologi, PT. Berau Coal, \\ ${ }^{2)}$ Fakultas Teknik Sipil \& Lingkungan, Institut Teknologi Bandung
}

\begin{abstract}
ABSTRAK
Pit E dan Pit 7B West adalah Pit yang berada di Blok-7 Tambang Binungan PT Berau Coal yang berdekatan dengan bibir sungai. Kedua pit ini memiliki resiko tinggi terhadap potensi banjir luapan air sungai. Sungai Kelay termasuk kategori Sungai Besar karena memiliki luas daerah aliran sungai (DAS) $7,027 \mathrm{~km}^{2}\left(>500 \mathrm{~km}^{2}\right)$ dan panjang $\pm 155 \mathrm{~km}$. Seiring dengan peningkatan target produksi PT Berau Coal (PTBC) tahun 2019 maka, bukaan penambangan menuju kearah utara mendekati bibir sungai. Kondisi ini akan berpotensi meluapnya air Sungai Kelay menuju Pit Blok-7 karena menerima kiriman banjir dari hulu. Banjir yang terjadi di area penambangan akan mempengaruhi kondisi keselamatan dan operasional penambangan serta ketercapaian produksi PTBC pada tahun 2019 secara keseluruhan. Berdasarkan historis kejadian banjir di Pit Blok-7 yang terjadi pada bulan Juni tahun 2017, luapan banjir dari Sungai Kelay mencapai elevasi +8.3MRL. Arah aliran banjir melalui area rawa pada sisi utara Pit dan menggenangi Pit 7B West. Sistem mitigasi telah dibangun di akhir tahun 2017 dan selesai pada akhir tahun 2018. Sistem mitigasi ini mencakup pengambilan data batimetri, HEC-HMS, HECRAS hingga analisis Neural Network yang menghasilkan waktu prediksi banjir untuk setiap titik pantau terdekat Pit yang telah ditentukan. Waktu prediksi banjir akan digunakan sebagai waktu tenggang untuk evakuasi alat beserta manusia. Sistem ini didukung oleh pembangunan instrumen monitoring otomatis berupa Automatic Rain Gauge dan Automatic Water Level Recorder pada titik hulu dan hilir Sungai Kelay, sehingga mampu menghasilkan analisis yang lebih cepat dan akurat terhadap kondisi aktual di lapangan serta dapat menggambarkan daerah terdampak banjir untuk kala ulang 50 tahun dan rekomendasi geometri tanggul penahan banjir yang sesuai. Sistem mitigasi dibagi menjadi 4 kode berdasarkan sisa waktu evakuasi mulai dari aman hingga bahaya yaitu hijau $(\geq 12 \mathrm{~h})$, kuning $(\leq 12 \mathrm{~h})$, oranye $(\leq 5 \mathrm{~h})$, dan merah $(\leq 2 \mathrm{~h})$. Dalam keberjalanannya selama periode Des'18-Juli'19, ketinggian elevasi muka air Sungai Kelay beberapa kali melewati batas hijau dan kuning. Ketika kondisi ini terjadi, instrumen pemantauan secara otomatis mengirimkan peringatan melalui surel, sms, serta fitur whatsapp sesuai dengan peruntukan tingkatan peringatannya. Sistem mitigasi ini juga memberikan peringatan secara otomatis melalui alarm yang terpasang di Control Room. Dengan adanya notifikasi secara otomatis, informasi peringatan dapat tersampaikan dengan cepat sehingga proses evakuasi di lapangan dapat segera dilakukan sesuai prosedur mitigasi bencana banjir PT Berau Coal.
\end{abstract}

Kata kunci: peringatan dini, mitigasi banjir, hec-hms, hec-ras, neural network

\begin{abstract}
Pit E and Pit 7B West are Pits located in Block-7 Binungan Mine Operation of PT Berau Coal which is adjacent to the river bank. The Pits have high risk of flood potential from the river. Kelay River belongs to the Great River category because the river basin area (DAS) is covering 7,027 $\mathrm{km}^{2}$ $\left(>500 \mathrm{~km}^{2}\right)$ and the length of $\pm 155 \mathrm{~km}$. In line with the increase of PT Berau Coal's (PTBC) production
\end{abstract}


target in 2019 resulting the advancement of Pits mining sequence towards the north approching the river bank. This condition will cause a high risk of overflowing the Kelay River water to Pit Block-7 especially when the heavy rain occurred in the upstream of the river. Flood that occurs inside the mining area will affect safety conditions of mining operations and the overall production achievements of PT Berau Coal in 2019. Historically, flood had been occurred in June, 2017 where the flood from Kelay River overflowed at +8.3 elevation through the swamp area in the north and inundated Pit $7 B$ West. Thus, the mitigation system has built at the end of 2017 and completed by the end of 2018. The mitigation system covered from bathymetry data collection, HEC-HMS, HEC-RAS to Neural Network analysis which results the water elevation prediction for each predetermined monitoring station. This prediction time will be used as lag time for the evacuation of equipments and human. This system is also integrated with automatic monitoring instruments as off Automatic Rain Gauge and Automatic Water Level Recorder at the Kelay River's upstream and downstream station. The overall system will generate fast and accurate analysis results based on actual condition, also describe affected flood area for 50 year return period, and recommendations for the appropriate flood embankment geometry in areas that need to be protected. Mitigation system is divided into 4 codes based on remaining evacuation time as off green $(\geq 12 h)$, yellow $(\leq 12 h)$, orange $(\leq 5 h)$, and red $(\leq 2 h)$. Along December 2018 to July 2019, several elevations were exceeded the green and yellow code. This event triggered the monitoring instrument to automatically sends warning notification via e-mail, message, and whatsapp. The system also provides an automatic warning through alarm installed in Control Room. With the automatic notifications, warning can be conveyed quickly to carry out field evacuation process immediately according to Flood Mitigation Procedure of PT Berau Coal.

Keywords: early warning, flood mitigation, hec-hms, hec-ras, neural network

\section{A. PENDAHULUAN}

Pit E dan Pit 7B West adalah pit yang terletak pada area konsesi PT Berau Coal, Blok-7 Tambang Binungan Mine Operation. Secara morfologi, Pit E dan Pit 7B West berada pada topografi original berupa gugusan perbukitan dengan selang ketinggian 101m-500m yang diselingi ceruk/gully dan area rawa yang berpotensi sebagai jalur masuknya air dan dataran banjir yang berasal dari Sungai Kelay yang terletak di arah utara pit.

Pada bulan Juni tahun 2017, telah terjadi banjir berasal dari Sungai Kelay yang mengalir melalui aliran original di sisi selatan sungai dan mendorong masuknya limpasan air dan lumpur sehingga menggenangi keseluruhan area tambang aktif di Pit 7B West hingga +8.3MRL. Kenaikan limpasan air diduga berasal dari tingginya hujan di hulu Sungai Kelay menyebabkan masuknya $52.570 \mathrm{~m} 3$ air beserta lumpur menggenangi Pit 7B West. Kejadian ini menyebabkan kerugian seperti property damage 1 unit Articulated Dump Truck, keterlambatan dalam pengambilan 47.000 ton batubara, biaya pengelolaan kualitas air Sungai Kelay yang tercemar pada Water Monitoring Point (WMP) 23 BT yang membutuhkan 13.8ton kapur, serta kebutuhan waktu untuk melakukan pemompaan sejumlah air dan lumpur yang masuk ke Pit 7B West.

Berdasarkan kejadian diatas dan rencana desain LOM (life of mine) yang akan mendekati dataran banjir Sungai Kelay, maka Sistem Peringatan Dini Banjir Sungai Kelay (Flood Early Warning System) dikembangkan di Desember 2017 dan rampung pada Oktober 2018 serta rekomendasi tanggulan banjir pada lokasi kritis dekat penambangan. Sistem ini meliputi analisis komprehensif terkait perilaku hujan di DAS Sungai Kelay hingga prediksi waktu tiba banjir dari hulu hingga ke area Tambang Binungan. 
Selanjutnya, sistem mitigasi berupa prosedur lapangan dibentuk sebagai kelanjutan dari sistem peringatan dini banjir Sungai Kelay.

\section{B. METODOLOGI PENELITIAN}

Pengembangan Sistem Peringatan Dini Banjir Sungai Kelay telah melalui beberapa tahap analisis komprehensif dimulai dari penentuan stasiun pantauan level air sungai sepanjang batas Pit Tambang Binungan dan Hulu Sungai Kelay sebanyak 6 stasiun, pengambilan data kedalaman Sungai Kelay melalui survei batimetri sepanjang $\pm 77 \mathrm{~km}$, analisis hidrologi Daerah Aliran Sungai (DAS) Sungai Kelay seluas $6348 \mathrm{~km}^{2}$, analisis curah hujan dan debit puncak, analisis hidrolika serta pasang surut air laut, dan analisis Neural Network.

\section{HASIL DAN PEMBAHASAN}

\section{C.1. Analisis Hidrologi}

Tambang Binungan PT Berau Coal memiliki sungai utama yaitu Sungai Kelay yang merupakan anak sungai dari Sungai Segah dan memiliki dua anak sungai yaitu Sungai Inaran dan Sungai Binungan. Sungai Kelay dan Sungai Segah kemudian alirannya menyatu ke Sungai Berau. Keseluruhan area penelitian serta stasiun pemantauan dapat dilihat pada Gambar 1.

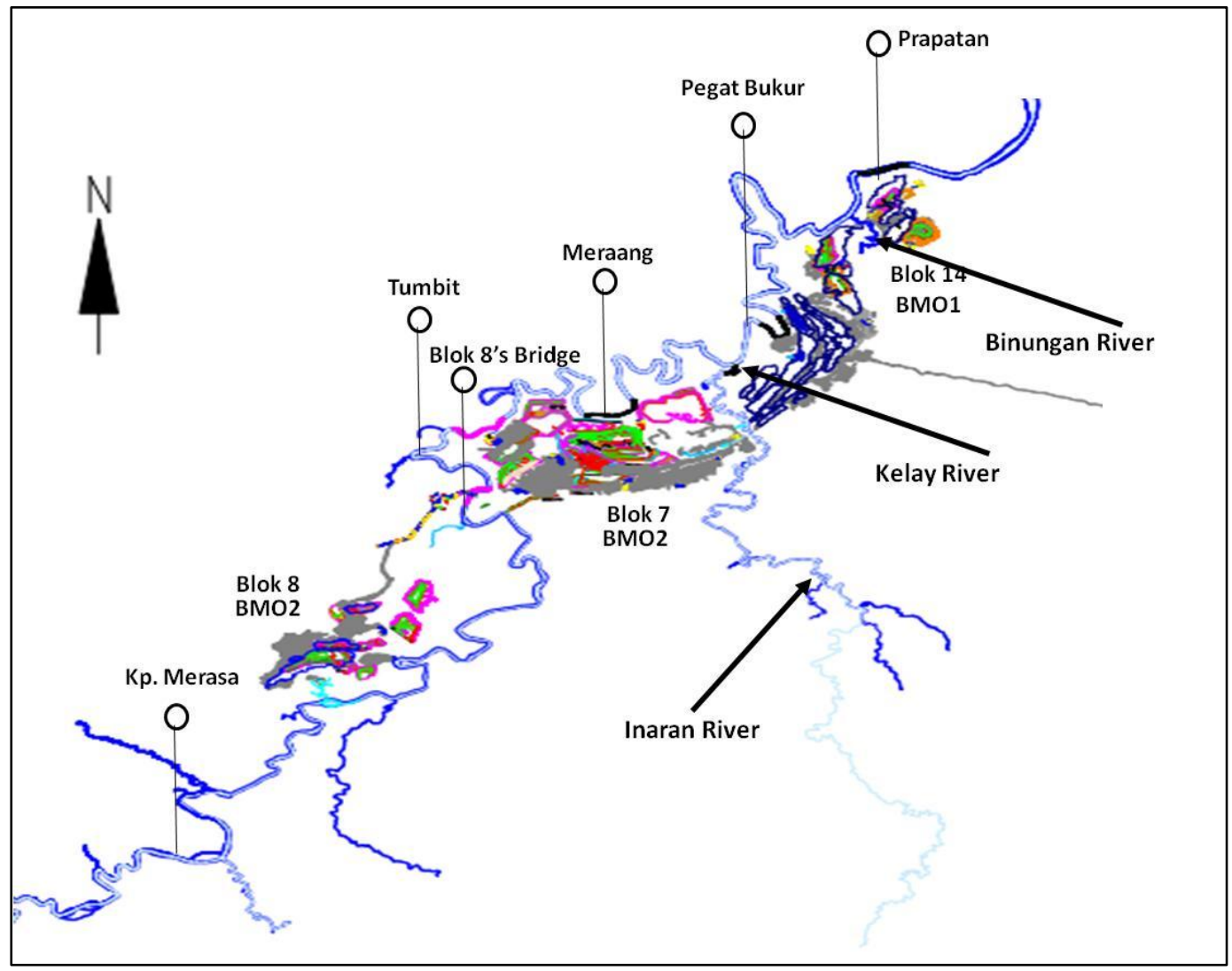

Gambar 1. Area Penelitian Flood Early Warning System

Data hujan dari stasiun hujan milik Badan Meteorologi dan Geofisika (BMG) Kalimarau dan stasiun hujan Binungan Mine Operation digunakan sebagai data awal untuk prediksi banjir dengan 
menggunakan metode hidrograf satuan sintetik dan kemudian melakukan metode komparasi dengan debit harian maksimum beberapa sungai di Kalimantan. Luasan DAS Sungai Kelay dan asosiasinya dapat dilihat pada Tabel 1.

Tabel 1. Luas Daerah Aliran Sungai Kelay, Sungai Segah, Inaran dan Binungan

\begin{tabular}{ccccl}
\hline No & DAS & Luas DAS $(\mathbf{k m 2})$ & Sungai & $\begin{array}{c}\text { Panjang Sungai } \\
(\mathbf{k m})\end{array}$ \\
\hline 1 & Merasa & 6348.601 & Kelay & 155.43 \\
2 & Segah & 6005.543 & Segah & 121.00 \\
3 & Inaran & 395.69 & Inaran & 34.18 \\
4 & Binungan & 116.30 & Binungan & 22.37 \\
\hline
\end{tabular}

Berdasarkan ukuran luasan, DAS Kelay berada di kisaran DAS Kedang Kepala-Muara Ancalong, DAS Kahayan-Palangkaraya, dan DAS Mentaya-Kualakurun dengan debit harian maksimum antara $941 \mathrm{~m}^{3} / \mathrm{s}-1533 \mathrm{~m}^{3} / \mathrm{s}$ untuk periode 25 tahunan dimana debit banjir maksimum diperkirakan lebih besar dari debit harian maksimum. Debit sungai harian maksimum Kalimantan dapat dilihat pada Tabel 2.

Tabel 2. Debit Harian Maksimum Sungai di Kalimantan

\begin{tabular}{|c|c|c|c|c|}
\hline $\begin{array}{c}\text { Luas Catchment } \\
\left(\mathrm{m}^{2}\right)\end{array}$ & $\begin{array}{l}\text { Debit } \\
\left(\mathrm{m}^{3} / \mathrm{s}\right)\end{array}$ & Nama Stasiun & $\begin{array}{c}\text { Periode } \\
\text { Pengukuran }\end{array}$ & Provinsi \\
\hline 4400 & 1533 & $\begin{array}{c}\text { Kedang Kepala - Muara } \\
\text { Ancalong }\end{array}$ & $1980-2009$ & Kalimantan Timur \\
\hline 25250 & 3779 & Mahakam - Melak & $1980-2009$ & Kalimantan Timur \\
\hline 15000 & 2967 & Kahayan - Palangkaraya & $1976-2003$ & Kalimantan Tengah \\
\hline 295 & 265 & Rungan - Tumbang Jutuh & $1978-1992$ & Kalimantan Tengah \\
\hline 5591 & 1168 & Kahayan - Kualakurun & $1977-2003$ & Kalimantan Tengah \\
\hline 4765 & 941 & Mentaya - Kualakurun & $1979-2006$ & Kalimantan Tengah \\
\hline
\end{tabular}

\section{C.2. Analisis Hidrolika}

Pemodelan muka air banjir diawali dengan membuat profil Sungai Kelay melalui Survei Batimetri sepanjang $\pm 77 \mathrm{~km}$ agar dapat merepresentasikan kondisi aktual Sungai Kelay. Titik kritis yang sekaligus dijadikan sebagai stasiun pantau berjumlah 5 titik di hilir sungai yaitu Prapatan, Pegat Bukur, Meraang, Tumbit Melayu, Jembatan Blok 8, dan 1 titik di hulu sungai yaitu staisun Kampung Merasa. Data survei batimetri kemudian diproses menggunakan software HEC-RAS untuk mendapatkan simulasi aliran sehingga dapat menggambarkan peristiwa rambatan banjir. Simulasi dilakukan dengan menggunakan syarat batas berupa debit sebesar $350 \mathrm{~m}^{3} / \mathrm{s}$ untuk kala ulang 25 tahun, kondisi pasang surut, kondisi muka air tertinggi dan muka air terendah. Hasil simulasi menunjukkan bahwa Sungai Kelay tidak dipengaruhi oleh pasang surut Sungai Berau dikarenakan elevasi dasar sungai di ruas atas dan tengah Sungai jauh di atas level muka air tertinggi Sungai Berau. Simulasi juga menghasilkan waktu rambatan puncak banjir pada stasiun pantau yang menggambarkan hubungan elevasi muka air dengan waktu tiba air pada stasiun tertentu. Misalnya debit di Kp. Merasa sejumlah " $\mathrm{x}$ " pada $t=0 j a m$ akan sampai di Jembatan Blok 8 pada $\mathrm{t}=6 \mathrm{jam}$ dengan debit yang sama. Waktu jeda dapat dilihat pada Tabel 3.

Tabel 3. Waktu Jeda di Beberapa Stasiun Pemantauan Banjir Tambang Binungan

\begin{tabular}{cccccccr}
\hline Merasa & $\begin{array}{c}\text { Jembatan } \\
\text { Blok } 8\end{array}$ & $\begin{array}{c}\text { Tumbit } \\
\text { Melayu }\end{array}$ & $\begin{array}{c}\text { Outlet WMP } \\
37 \text { BT }\end{array}$ & Meraang & Inaran & $\begin{array}{c}\text { Pegat } \\
\text { Bukur }\end{array}$ & Prapatan \\
\hline 0 jam & 6 jam & 9 jam & 9 jam & 11 jam & 14 jam & 16 jam & 21 jam \\
\hline
\end{tabular}


Waktu jeda kemudian akan digunakan sebagai masukan pada simulasi banjir dengan metode Neural Network.

\section{C.3. Analisis Neural Network}

Waktu jeda pada sistem ini merupakan waktu yang efektif untuk melakukan tanggap darurat serta hal yang krusial dalam penentuan efektifitas sistem peringatan dini banjir. Model hubungan antara muka air sungai di Merasa dan muka air sungai di stasiun pemantauan lainnya dihubungankan menggunakan pendekatan Neural Networks. Pendekatan ini merupakan bagian dari Artificial Inteligence yang meniru jaringan saraf manusia dalam mentransformasi sebuah informasi. Sistem ini menggunakan tiga layer sebagai input pada Software Matlab yaitu input layer, hidden layer, dan output layer. Skema Neural Networks pada sistem FEWS dapat dilihat pada Gambar 2.

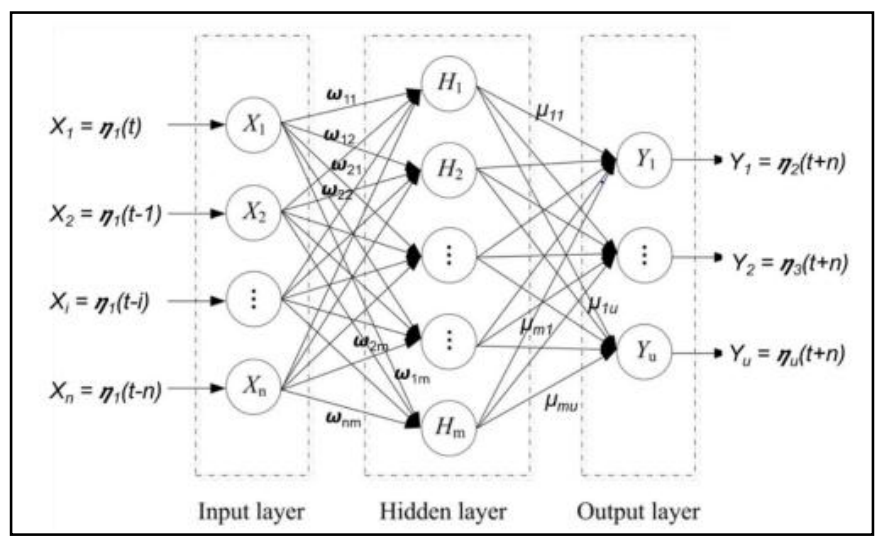

Gambar 2. Skema Neural Networks pada sistem FEWS

Jaringan Neural Networks pada dasarnya mencari persamaan hubungan antara input dan output pada layer percobaan. Input Layer merupakan kondisi muka air di Sungai Berau, aliran Sungai Segah, dan elevasi muka air di Kp. Merasa. Output Layer adalah hasil prediksi muka air di Jembatan Blok 8 beberapa jam kemudian setelah kejadian di stasiun Kp. Merasa. Hasil simulasi NN menghasilkan koefisien pemberat yang optimal sehingga memberikan hasil yang akurat. Perbandingan hasil prediksi NN dengan data disajikan pada Gambar 3.

\section{C.4. Sistem Mitigasi dan Instrumentasi}

Sistem peringatan dini banjir (FEWS) menurut Werner dan Kwadijk, 2005 perlu dirancang melalui beberapa tahap agar efektif yaitu:

- Deteksi: memantau waktu nyata dan memproses untuk kemudian diolah menjadi informasi mengenai banjir yang mungkin terjadi. Informasi kemudian dijadikan sebagai peringatan sebagai prediksi banjir.

- Prediksi: tahapan ini terdiri dari melakukan prediksi terhadap curah hujan, tinggi muka air, debit aliran, dan waktu datangnya banjir. Keseluruhan data ini kemudian diteruskan sebagai peringatan.

- Peringatan dan diseminasi: tahapan ini merupakan tahap krusial dalam sistem peringatan dini banjir yang menggunakan informasi dari 2 tahap sebelumnya. Pihak yang bertanggung jawab pada proses mitigasi kemudian menyebarkan informasi melalui jalur komunikasi yang telah ditentukan sehingga dapat meminimalisir resiko yang mungkin terjadi. 
- Tanggap darurat: tahapan ini berupa proses tanggap terhadap isu peringatan banjir. Personil yang tanggap secara cepat dan tepat sangat dibutuhkan agar tindakan dapat dilakukan secara efektif. Jika tanggap darurat dilakukan secara efektif, maka kerugian materil maupun non materil dapat diminimalisir.

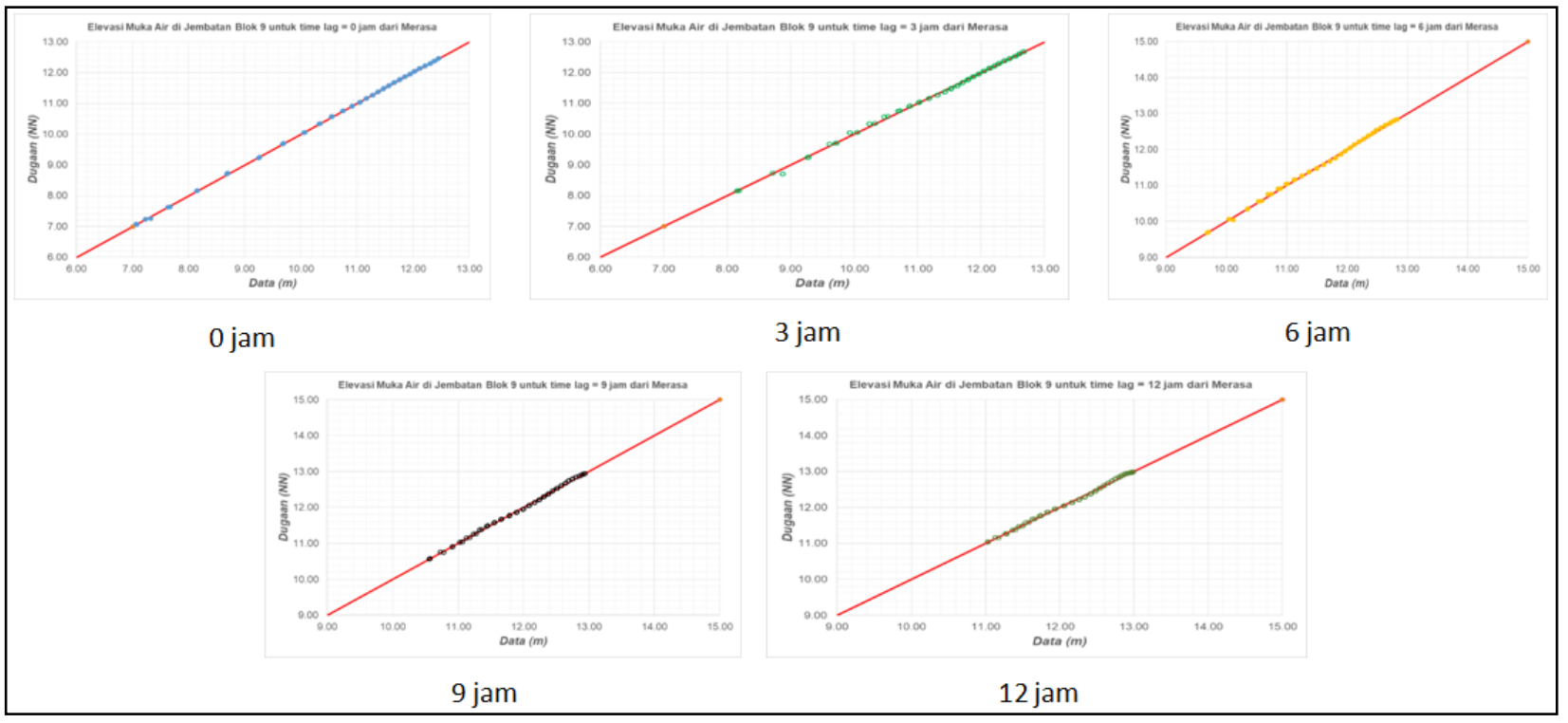

Gambar 3. Hasil Perbanding Prediksi NN dan Input Data

Diagram sistem peringatan dini banjir (FEWS) dapat dilihat pada Gambar 4 sebagai berikut:

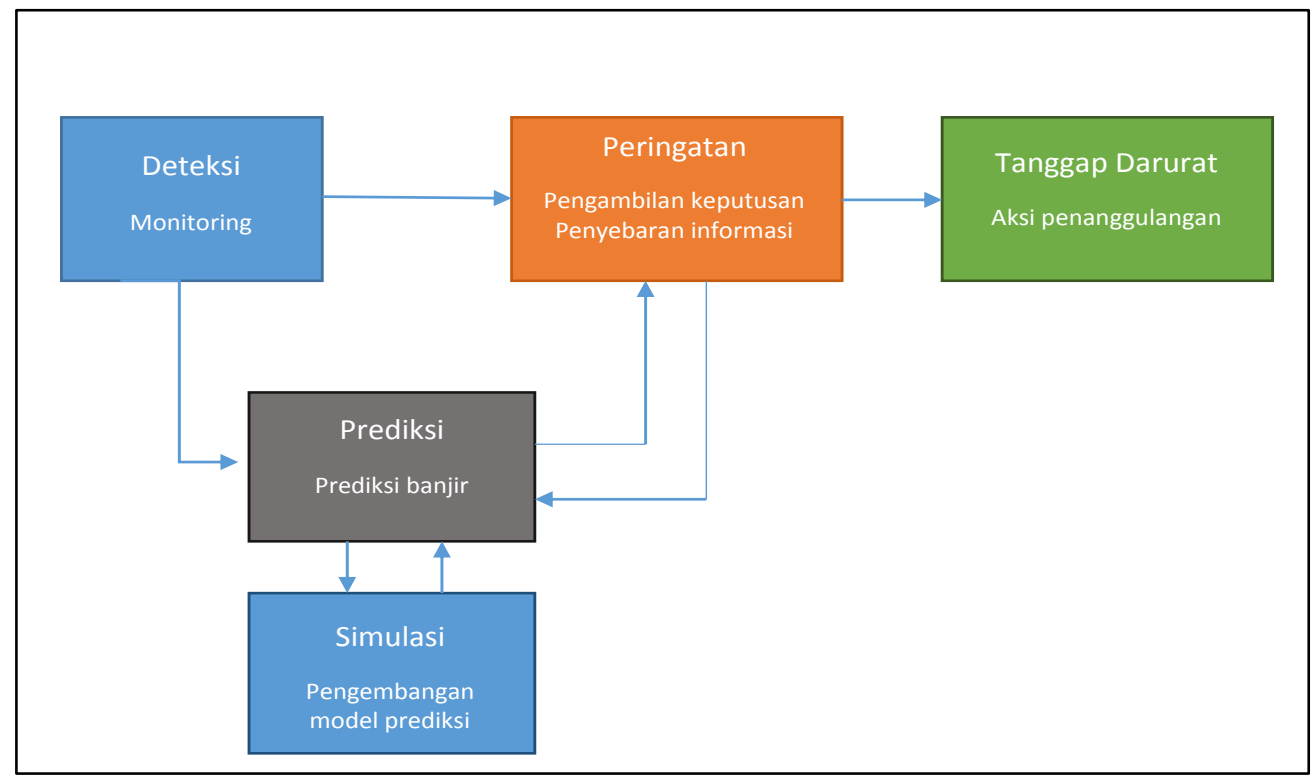

Gambar 4. Diagram Sistem Peringatan Dini Banjir Tambang Binungan

Sistem peringatan dini adalah suatu sistem atau rangkaian proses pengumpulan dan analisis data serta diseminasi informasi tentang keadaan darurat yang berfungsi untuk memberitahukan terkait bencana yang akan terjadi atau kejadian alam lainnya. Tujuan dari sistem ini dibentuk pada Tambang Binungan adalah agar dapat mengantarkan informasi kepada para pekerja tambang dengan harapan pekerja dapat merespon informasi tersebut dengan cepat dan tepat. Kesiapsiagaan dan kecepatan reaksi diperlukan 
karena adanya kondisi kritis dan waktu mitigasi yang sempit. Waktu tenggang untuk setiap stasiun pengamatan dapat dilihat pada Gambar 5.

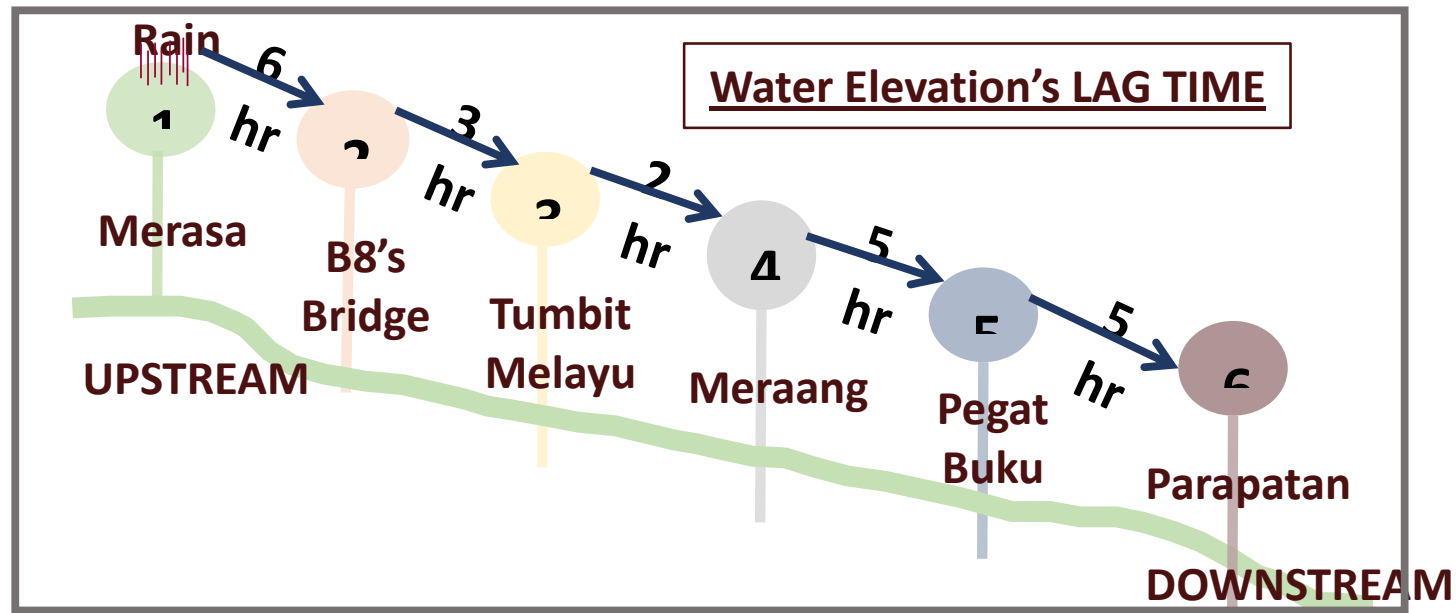

Gambar 5. Lag Time Staisun Pemantauan FEWS Tambang Binungan

Aristektur sistem peringatan dini banjir menggunakan alat pengukur curah hujna otomatis (ARG) dan alat deteksi ketinggian muka air otomatis (AWLR) sebagai instrumentasi utama sebagai masukan data pada simulasi. Keseluruhan simulasi selanjutnya menerjemahkan data menjadi prediksi muka air banjir di setiap stasiun serta waktu tenggang evakuasi. Jika pada titik pantau tersebut tidak terdapat tanggulan penahan banjir, maka sistem peringatan dini digunakan. Peringatan diberikan dalam 4 tahap yaitu hijau, kuning, oranye, dan merah berdasarkan nilai elevasi maksimum yang dapat ditanggulangi seperti pada Tabel 4 .

Tabel 4. Maksimum Ketinggian Muka Air pada Stasiun Pantauan Banjir Tambang Binungan

\begin{tabular}{cccc}
\hline Kode & Waktu Tenggang (Jam) & $\begin{array}{c}\text { Lokasi Stasiun Pantauan } \\
\text { Banjir }\end{array}$ & $\begin{array}{c}\text { Tinggi Muka Air } \\
\text { Maksimum }\end{array}$ \\
\hline Merah & $\leq 02: 00$ & Jembatan Blok 8 & 11 \\
Oranye & $\leq 05: 00$ & Tumbit Melayu & 10 \\
Kuning & $\leq 12: 00$ & Meraang & 8 \\
Hijau & $\geq 12: 00$ & Pegat Bukur & 8 \\
& & Outlet WMP 37 BT & 8 \\
& & Inaran & 9 \\
\hline
\end{tabular}

Jika kondisi kritis yaitu oranye dan merah terjadi, instrumentasi secara otomatis akan memberikan peringatan sesuai dengan tingkatan warna pada kondisi aktual dimana alarm terpasang pada Control Room Head Office PT Berau Coal. Secara bersamaan, instrumentasi juga akan mengirimkan peringatan melalui sms kepada tim atau penanggung jawab yang bertugas untuk menjalankan fungsi-fungsi manajemen sistem peringatan dini yang termasuk di dalamnya melakukan fungsi manajemen resiko banjir seperti penanggulangan, pencegahan, risk assessment, dan evaluasi. Tampilan peringatan berupa alarm dan sms dapat dilihat pada Gambar 6. 


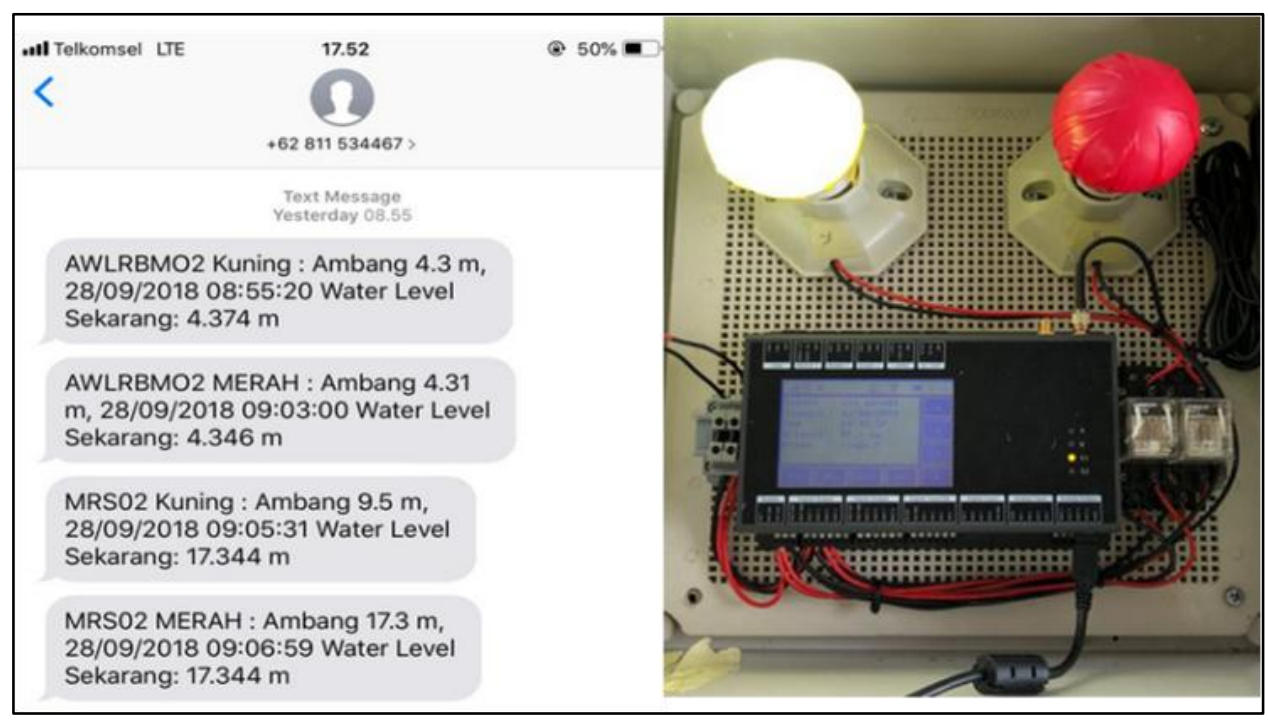

Gambar 6. Peringatan Berupa Alarm dan SMS

\section{KESIMPULAN}

Pengembangan Sistem Peringatan Dini Banjir Sungai Kelay telah selesai dilakukan pada bulan Oktober 2018 dan telah berjalan sampai saat ini. Prediksi banjir dilakukan dengan menggunakan analisis komprehensif dimulai dari analisis hidrologi, analisis hidrolika serta pendekatan Artificial Inteligence berupa Neural Networks. Data masukan yang diperlukan berupa debit air Sungai Kelay, kenaikan muka air, serta pasang surut di beberapa stasiun pantauan akan diproses oleh Neural Networks untuk kemudian menghasilkan prediksi banjir beserta waktu tibanya. Terdapat 5 stasiun yang berfungsi sebagai stasiun pantau terkait adanya banjir di Tambang Binungan. Jika terdapat suatu daerah yang belum memenuhi standar tanggul penahan banjir, maka sistem peringatan dini banjir Sungai Kelay diberlakukan dan lokasi tersebut telah diidentifikasi dan dilakukan sosialisasi terhadap sistem mitigasinya.

\section{DAFTAR PUSTAKA}

PT. LAPI ITB (2018): Basic Design dan Sistem Peringatan Dini untuk Pengamanan Banjir Sungai Kelay Site Binungan 2018, Final Report, Institut Teknologi Bandung, Bandung, 168 - 183.

Werner, M G F., Schellekens, J., Kwadijk, JCJ. (2005): Flood Early Warning Systems for Hydrological (sub) Catchments. Encyclopedia of Hydrological Sciences vol. 1, John Wiley \& Sons Ltd, Part 2, 23.

World Meteorological Organization (WMO) (2011): Manual on Flood Forecasting and Warning, WMO No. 1072.

Kementrian Pekerjaan Umum (2012): Pedoman Penyusunan Sistem Peringatan Dini dan Evakuasi untuk Banjir Bandang, 7-15.

Nugroho, Hadisusanto (2011): Aplikasi Hidrologi, Penerbit Jogja Mediautama, Yogyakarta.

Triamodjo, Bambang (2014): Hidrologi Terapan, Beta Offset, Yogyakarta, 107-126.

US Army Corps of Engineer Hydrologic Engineering Center (2016): HEC-RAS River Analysis System Hydraulic Reference Manual, Version 5.0, Davis, California, 2-52 - 2-67.

PT. Solusi Tambang Indonesia (2017): Modul Pelatihan Model Hidrodinamika Menggunakan Watershed Modelling System (WMS) Lanjutan, Final Report, Bandung. 